\title{
PENGARUH PERSEPSI KEMANFAATAN DAN PERSEPSI KEMUDAHAN PENGGUNAAN TERHADAP PENGGUNAAN LAYANAN APLIKASI GOFOOD
}

\author{
Rusminah $\mathrm{HS}^{1}$, Hilmiati $^{2}$ \\ ${ }^{1}$ Fakultas Ekonomi dan Bisnis, Universitas Mataram rosewahyu99@gmail.com \\ ${ }^{2}$ Fakultas Ekonomi dan Bisnis, Universitas Mataram hilmiatifauzi62@gmail.com

\begin{tabular}{ll|lll}
\hline Article history & \multicolumn{3}{l}{} \\
\hline Dikirim tanggal & $: 11 / 02 / 2021$ & Diterima tanggal & $: 07 / 03 / 2021$ \\
Revisi pertama tanggal & $: 02 / 03 / 2021$ & Tersedia online tanggal & $:$ & $23 / 03 / 2021$ \\
\hline
\end{tabular}

\begin{abstract}
ABSTRAK
Penelitian bertujuan untuk menguji pengaruh persepsi kemanfaatan dan perspsi kemudahan penggunaan terhadap Aplikasi GoFood pada konsumen di kota Mataram. Jenis penelitian ini adalah penelitian asosiatif. Populasi dalam penelitian ini adalah masyarakat kota Mataram yang menggunakan aplikasi GoFood, dengan sampel sebanyak 100 responden. Teknik pengambilan sampel dengan teknik Non-Probability sampling dengan metode Purposive sampling. Teknik pengumpulan data yang digunakan, angket dan dokumentasi. Tehnik analisia untuk menguji hipotersis adalah analisa regresi berganda. Hasil penelitian menunjukkan bahwa persepsi mamfaat dan persepsi kemudahan berpengaruh positif dan signifikan terhadap penggunaan aplikasi GoFood pada konsumen di kota Mataram, sehingga disarankan kepada pada pihak Gojek untuk lebih mengoftimalkan pelayanan dan jaminan keaamanan serta terus melakukan pemulihan dengan meningkatkan kemudahan teknologi, agar konsumen dapat berinteraksi dengan lebih mudah, nyaman dan aman.
\end{abstract}

Kata Kunci: persepsi manfaat, persepsi kemudahan, penggunaan aplikasi GoFood.

\section{ABSTRACK}

The Research is conducted to find out perceived usefilness and perceived ease of use to use toward the using of GoFood application at consumers' in Mataram city. This type of research is an associate study. The population in this research is Mataram city comminity that uses GoFood application, with a sample of 100 responden. Sample technique use Non probability samplig with Purposive sampling method. The data-collection techniques used, angket and documentation. The data analysis technique which is applied to examine the hypothesis is double linear regression. The research result shows that there is a positive influence and significant of perceived usefulness and petceived ease of use toward the using of GoFood application at consumers' in Mataram city, hence it is recommended to Gojek workers to make more impact on services and security and to continue recovery by promoting technological ease, enabling consumers to interact more easily, conveniently and safely.

Keyword: Perceptions usefullness, perceptions of ease, use of the GoFood applications.

\section{PENDAHULUAN}

Perkembangan zaman yang maju dewasa ini, menimbulkan pertumbuhan teknologi dan pertumbuhan dunia usaha yang semakin pesat. Persaingan antar perusahaan pun terjadi begitu ketat, salah satunya dalam bidang transportasi. Transportasi diartikan sebagai pemindahan barang dan manusia dari tempat asal ke tempat tujuan. Jasa transportasi merupakan suatu sarana yang dibutuhkan oleh 
masyarakat dalam kehidupan sehari-hari. Orang yang mempunyai kendaraan pribadi tidak akan kesulitan untuk melakukan aktivitasnya sehari-hari, tetapi bagi yang tidak mempunyai kendaraan pribadi, maka transportasi umumlah yang akan menjadi sarana bagisetiap aktivitasnya (Supriyanto dalam Zakaria,2013).

Gojek merupakan salah perusahaan yang membuat terobosan baru dalam bidang transportasi umum berbasis teknologi informasi. Mengingat pertumbuhan pengguna yang semakin pesat, tidak perlu lagi menghabiskan waktu dan tenaga untuk mencari transportasi umum, karena Gojek menawarkan reservasi secara online melalui aplikasi pada Smartphone sehingga memudahkan dalam melakukan transaksinya dan akan menghasilkan respon yang berbeda dari penggunanya.

Salah satu model yang dapat digunakan untuk mengukur penerimaan sistem informasi oleh penggunanya adalah Technology Acceptance Model (TAM). Model TAM ini diperkenalkan oleh Davis (1989) yang mengembangkan kerangka pemikiran mengenai minat untuk menggunakan Tekhnologi berdasarkan persepsi manfaat (Perceived of usefulness) dan persepsi kemudahan penggunaan (Perceived ease of use). Persepsi manfaat merupakan suatu fase, seseorang percaya bahwa pemakai suatu sistem tertentu akan dapat menambah prestasi kerja seseorang. Thompson (1991) juga menyatakan bahwa indiviudu akan menggunakan tekhnologi informasi jika orang tersebut memiliki pemahaman mengenai manfaat atau kegunaan yang baik. Sedangkan persepsi kemudahan merupakan penggunaan dapat menyakinkan pengguna bahwa teknologi yang akan diaplikasikan adalah suatu hal yang mudah dan bukan beban bagi mereka. Davis (1989) menyatakan bahwa persepsi kemudahan merupakan sebuah tingkatan dimana seseorang percaya bahwanya penggunaan sistem tertentu tertentu mampu mengurangi usaha seseorang dalam mengerjakan sesuatu.

Perkembangan terkini masyarakat Indonesia khusus masyarakat di kota Mataram cenderung menggunakan sesuatu yang baru dan terbiasa untuk dilayani. Dengan menggunakan teori TAM, peneliti akan melakukan penelitian mengenai jasa transfortasi online Gojek. Menurut jejak pendapat APP 2016, Gojek lebih banyak diminati masyarakat Indonesia dan lbih unggul beberapa aspek disbanding pesaingnya, Gojek hadir pertama kali menawarkan jasa dengan memanfaatkan aplikasi dibidang tekhnologi informasi di Mataram pada tahun 2017 dengan menyajikan beberapa aplikasi GO-Food, Go-Send, Go-Ride dan Go-Car. Dari beberapa aplikasi yang ditawarkan Go-Food merupakan aplikasi yang paling banyak diminati, karena aplikasi GoFood membuat waktu menjadi lebih efisien dalam beraktifitas dan tidak dibutuhkan banyak usaha untuk berinteraksi dengan aplikasi pesanan.

\section{TINJAUAN TEORITIS}

\section{Persepsi Kemanfaatan}

Persepsi Kemanfaatan didefinisikan sebagai sejauhmana seseorang meyakini bahwa penggunaan sistem informasi tertentu akan meningkatkan kinerjanya. Jika seseorang merasa percaya bahwa system berguna maka dia akan menggunakannya. Sebaliknya jika seseorang merasa percaya bahwa system informasi kurang berguna maka dia tidak akan menggunakannya (Santoso, 2014). Menurut Davis dalam Rajendra 
(2014) mendefinisikan sebagai suatu ukuran dimana penggunaan suatu teknologi dipercaya akan mendatangkan manfaat bagi orang yang menggunakannya.

Hal ini sejalan dengan yang diungkapkan Wang dalam Bhilawa. L (2010) bahwa persepsi kemanfaatan didefinisikan dimana seseorang percaya dengan mengguanakan suatu system dapat meningkatkan kinerja mereka.

Konsep persepsi kemanfatan menunjukkan keyakinan pemakai pada kontribusi sistem informasi terhadap kinerja pemakai. Dengan kata lain tingkat kepercayaan seseorang bahwa pengguanaan system akan mendatang manfaat dan meningkatkan kinerjanya.

Indikator persepsi kemanfaatan yang dirasakan dapat dikelommpokka menurut Chin dalam Trissantama (2012):

1. Menjadikan pekerjaan lebih mudah

2. Bermanfaat

3. Meningkatkan produktivitas

4. Mempertinggi sfektivitas

5. Mengembangkan kinerja pekerjaan.

H1 : Semakin tinggi tingkat kemanfaatan semakin tinggi pula penggunaan layanan aplikasi GojekFood.

\section{Persepsi Kemudahan Penggunaan (Perceived Ease of Use)}

Menurut Davis dalam Winayu (2013) Persespsi kemudahan penggunaan (Perceived Ease of Use) merupakan suatu tingkat atau keadaan di mana dengan menggunakan system tertentu tidak diperlukan usaha apapun. Nasution (2014) menyatakan bahawa penggunaan teknologi informasi mempercayai bahwa teknologi informasi yang lebih fleksibel, mudah dipahami dan mudah pengoperasiannya sebagai karakteristik kemudahan penggunaan. Kemudahan yang mengarah pada keyakinan individu bahwa pemakai sistem tersebut tidak banyak memerlukan usaha.

Salah satu faktor yang menyebabkan pemakai menerima atau menolak system adalah keterkaitan dengan penggunaan system. Pengguna cenderung untuk menggunakan atau tidak aplikasi yang dianggap sebagai sesuatu yang mereka yakini akan membantu kinerja mereka dalam melakukan pekerjaan. Penerimaan system informasi berarti pemakai mendukung, berpartisipasi dan menggunakan sistem informasi tersebut dalam menunjang kegiatan operasional sehari-hari dengan menggunakan ukuran yaitu kemudahan penggunaan system dan kegunaan sistem.

Kemudahan penggunaan sistem memiliki arti bahwa bentuknya tidak membingungkan, jelas dan mudah dimengerti. Sedangkan yang dimaksud kegunaan sistem berarti suatu tingkat dimana seseorang percaya bahwa dalam menggunakan sistem tertentu akan lepas dari suatu usaha tertentu melalui prose penguasaan aplikasi tertentu.

Indikator persepsi kemudahan penggunan, menurut Davis dalam Andryanto (2016) adalah sebagai berikut:

1. Interaksi individu dengan sistem jelas dan mudah dimengerti.

2. Tidak dibutuhkan banyak usaha untuk berinetraksi dengan sistem tersebut.

3. Sistem mudah digunakan.

4. Mudah mengoperasikan sistem dengan apa yang ingin individu kerjakan. 
H2 : Semakin tinngi tingkat kemudahan semakin tinggi pula tingkat penggunaan layanan fitur GoFood di aplikasi Gojek.

\section{Aplikasi}

Menurut Kadir (2008) aplikasi adalah program yang dibuat oleh pemakai uang ditunjukkan untuk melakukan suatu tugas khusus. Sedangkan program aplikasi adalah program siap pakai atau program yang direka untuk melaksanakan suatu fungsi bagi pengguna atau aplikasi yang lain. Aplikasi juga diartikan sebagai penggunaan atau penerapan suatu konsepyang menjadi pokok pembahasan atau sebagai program komputer yang dibuat untuk menolong manusia dalam melaksanakan tugas tertentu.

Indikator penggunaan aplikasi menurut Torkazd dalam Dastgir (2012) sebagai berikut:

1. Isi (content)

2. Akurasi (accuracy)

3. Bentuk (format)

4. Kemudahan (ease)

5. Ketepatan waktu (timeliness).

\section{Kerangka Konseptual}

Teknologi mempunyai peranan penting dalam memenuhi kebutuhan manusia yang semakin meningkat. Davis dalam Jogiyanto (2007) beberapa model yang dibangun untuk menganalisis dan memahami faktor-faktor yang mempengaruhi diterimanya penggunaan teknologi, diantaranya yang tercatat dalam berbagai literature dan referensi hasil riset di bidang teknologi adalah Theory of Reasoned Action (TRA), Theory of Planned Behavior (TPB) dan Technology Accetance Model (TAM). Menurut Davis (1989) TAM merupakan salah satu teori tentang penggunaan sistem teknologi informasi yang dianggap sangat berpengaruh dan umumnya digunakan untuk menjelaskan penerimaan individual terhadap penggunaan sistem teknologi informasi. TAM menambahkan dua kontruk utama, yaitu persepsi kemanfaatan (perceived usefulness) dan persepsi kemudahan (perceived ease of use). Berdasarkan pemikiran diatas, maka dapat digambarkan kerangka konseptual sebagai berikut: (X1) Persepsi kemafaaatan, (X2) Persepsi Kemudahan, (X3). Penggunaan Aplikasi GoFood

Berdasarkan pemikiran di atas, maka dapat digambarkan kerangka konseptual sebagai berikut:

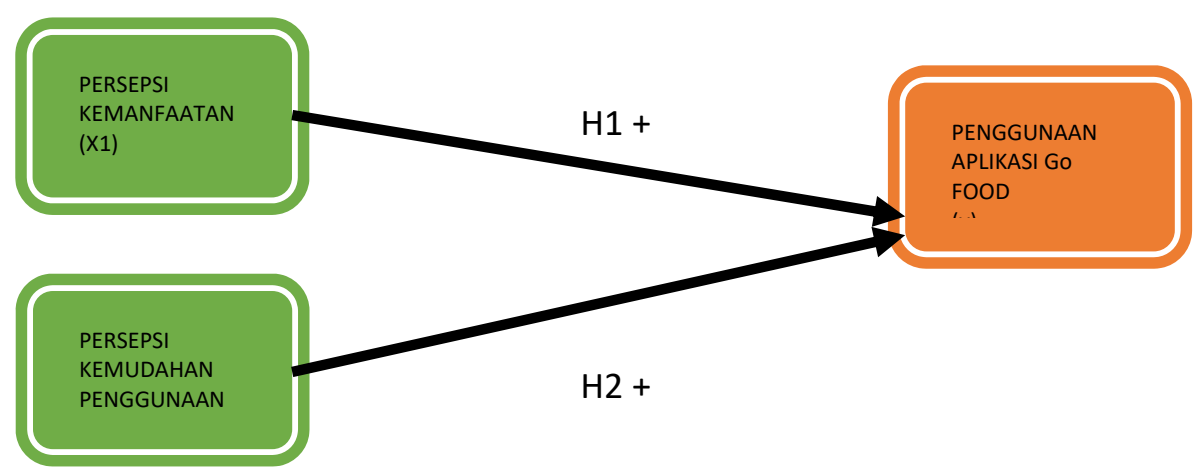

Gambar 1. Kerangka Konseptual

METODE PENELITIAN

90 | Pengaruh Persepsi Kemanfaatan Dan Persepsi Kemudahan Penggunaan... 


\section{Jenis Penelitian}

Penelitian ini merupakan penelitian asosiatif dimana persepsi kemanfaatan dan persepsi kemudahan pengguanan sebagai variabel yang mempengaruhi (variabel indevenden) dan penggunaan aaaaplikasi GoFood sebagai variabel yang dipengaruhi (variabel devenden).

\section{Lokasi Penelitian}

Penelitian ini akan dilaksanakan di kota Mataram Nusa Tenggara Barat. Alasan memilih lokasi ini karena driver Gojek banyak ditemukan di kota Mataram. Ada 50 driver Gojek yang tersebar di sejumlah titik di kota mataram.

\section{Populasi dan Sampel}

Populasi dalam penelitian ini adalah masyarakat kota Mataram yang menggunakan aplikasi GoFood. Adapun jumlah sampel adalah 100 orang, dimana besaran ini sudah dapat dikatakan layak untuk digunakan dalam penelitian kuantitatif (Sugiyono, 2018). Teknik pengambilan sampel dengan menggunakan teknik NonProbability sampling dengan metode Purposive sampling dengan kriteria sampel yang digunakan adalah masyarakat yang pernah menggunakan layanan fitur GoFood di aplikasi Gojek yang berdomisili di kota Mataram dan pendidikan minimal SMA.

\section{Jenis dan Sumber Data}

Jenis data yang digunakan dalam penelitian ini adalah data kualitatif dan kuantitatif. Sedangkan sumber data yang dipergunakan adalah data primer dan data skunder. Data primer diperoleh langsung dari penyebaran kuisioner kepada para pengguna layanan aplikasi GoFood di kota Mataram dan data skunder dipoeroleh dari literatur dan sumber- sumber lain yang mendukung antara lain internet dan beberapa nara sumber bersangkutan.

\section{Teknik dan Alat pengumpulan Data}

Teknik pengumpilan data yang digunakan dalam penelitian ini adalah angket dan dokumentasi. Angket merupakan teknik pengumpulan data yang dilakukan dengan cara memberikan seperangat pertanyaan tertulis kepada responden. Sedangkan dokumentasi dipergunakan untuk meramu dan menempatkan terminologi dari sumbersumber teori.

Alat pengumpulan data yang digunakan adalah kuisioner. Tipe dan bentuk pertanyaan yang digunakan adalah pertanyaan tertutup yaitu pertanyaan yang mengharapkan jawaban singkat dan mengharapkan responden untuk memilih salah satu alternatif jawaban dari setiap pertanyaan yang telah tersedia. Kuesioner-kuesioner tersebut akan diberikan langsung atau diupload di website goole form dan memberikan link nya kepada responden

\section{Uji Asumsi Klasik}

1. Uji Normalitas 
Uji Normalitas dilakukan untuk mengetahui apakah data yang digunakan dalam model regresi berdistribusi normal atau tidak (Ghozali, 2012).

2. Uji Multikolinearitas

Menurut Ghozali (2012) uji Multikolinearitas digunakan untuk melihat ada atau tidaknya korelasi yang tinggi antara variabel-variabel bebas dalam suatu model regresi linier berganda.

3. Uji Heteroskedatisitas

Uji Heteroskedatisitas bertujuan untuk menguji apakah dalam model regresi terjadi ketidaksamaan varians dari residual satu pengamatan ke pengamatan lain (Ghozali, 2012)

Analisis Regresi Linier Berganda digunakan untuk mengukur pengaruh lebih dari satu variabel bebas terhadap satu variabel terikat (Sugiono, 2018). Pada penelitian ini analisis Regresi Linier berganda digunakan untuk mengetahui pengaruh variabel Persepsi Kemanfaatan dan Persepsi Kemudahan penggunaan terhadap penggunaan GojekFood pada masyarakat di kota Mataram. Adaoun model regresi linier berganda penelitian ini ditunjukkan dengan persamaan sebagai berikut:

$\mathrm{Y}=\mathrm{a}+\mathrm{b} 1 \mathrm{X} 1+\mathrm{b} 2 \mathrm{X} 2 \mathrm{e}$

\section{Uji Signifikansi Parsial (Uji t)}

Uji statistic t menunjukkan seberapa jauh pengaruh suatu variabel independen secara individual dalam menerangkan variabel dependen secara parsial. Uji ini dilakukan dengan membandingkan signufikansi t hitung dengan $t$ table.

\section{HASIL DAN PEMBAHASAN}

\section{Uji Kualitas Instrumen}

\section{Uji Validitas}

Uji Validitas dimaksudkan untuk menyatakan sejauh mana data yang tertampung pada suatu kuesioner dalam mengukur apa yang diukur. Pengujian validitas pada penelitian ini digunakan pada tiga variabel yaitu, perceived usefulness, perceivedease of use, dan penggunaan aplikasi layanan GoFood pada masyrakat di Kota Mataram. Adapun korelasi product moment pada program SPSS for windows dengan level signifikan sebesar 5 persen Teknik ini membandingkan nilai $r$ hitung dengan $r$ tabel dimana $r$ tabel sendiri dicari pada signifikansi 0,05 dan jumlah data $(n)=20$ maka instrument dikatakan valid, dan jika sebaliknya di nyatakan tidak valid.

Rumus korelasi product moment adalah sebagai berikut:

$$
r_{x y=} \frac{n\left(\sum x y\right)-\left(\sum x \sum y\right)}{\sqrt{\left[n \sum x^{2}\right]} \sqrt{\left[n \sum y^{2}-\left(\sum y\right)\right]^{2}}}
$$

Keterangan:

$\begin{array}{ll}\mathrm{r} & \text { : koefisien korelasi product moment } \\ \mathrm{n} & : \text { jumlah subjek } \\ \mathrm{x} & :(\mathrm{X} 1, \mathrm{X} 2) \\ \mathrm{y} & :(\mathrm{Y}) \\ \mathrm{Ex} & : \text { jumlah sekor item }\end{array}$


$\Sigma y \quad$ : jumlah sekor total

$\Sigma x y \quad$ : jumlah perkalian antara sekor item dan sekor total

$\Sigma \mathrm{x}^{2} \quad$ : kuadran skor item

$\Sigma \mathrm{y}^{2} \quad$ : kuadran skor total

Data dikatakan valid apabila, data dari hasil penyebaran kuesioner dianggap efektif untuk mengungkapkan masalah dan mewakili dari 20 sampel. Teknik yang digunakan yaitu dengan melakukan korelasi antar skor butir pernyataan dengan total skor variabel. Berikut $r$ hitung dan $r$ tabel pada table.

Uji validitas telah dilakukan dengan menggunakan 20 sampel pertama. Penggunaan 20 sampel pertama ini, mengingat jumlah seluruh sampel adalah sebanyak 100 sampel. Dimana bila korelasi product momen $<$ dari $\mathrm{r}$ tabel menunjukkan bahwa pernyataan tidak mampu mengukur variabel yang akan diukur, dan apabila $r$ hitung $>r$ tabel maka pernyataan tersebut valid (Ghozali, 2012). Dilihat dari hasil perhitungan yg dilakukan menunjukkan bahwa nilai korelasi dari setiap skor butir 13 pernyataan, variabel yang terdapat dalam penelitian ini bahwa $r$ tabel diketahui sebesar 0,422 dan setiap $r$ hitungnya lebih besar dari $r$ tabel yang berarti semua pertanyaan valid. Sehingga dapat disimpulkan bahwa semua item pernyataan mampu mengukur variable perceived usefulness, perceivedease of use, dan penggunaan aplikasi layanan GoFood pada masyrakat di Kota Mataram.

2. Uji Reliabilitas

Dalam penelitian ini digunakan formula alfa Cronbach.Instrumen sebuah penelitian dapat dikatakan reliabel apabila memiliki Cronbach Alpha $>0,70$ (Ghozali, 2012). Adapun hasil uji reliabilitas dalam penelitian ini dapat dilihat pada sebagai berikut:

Tabel 1. Uji Reabilitas

\begin{tabular}{|c|c|}
\hline Cronbach's Alpha & N of Items \\
\hline .908 & 13 \\
\hline
\end{tabular}

$0.908=90.8 \%$

Kriteria Ghozali (2012): Nilai Cronbacth $>70 \%=$ Riliabel

$90.8 \%>70 \%=$ Riliabel

\section{Alat Analisis Data}

1. Uji Normalitas

Hasil uji normalitas menggunakan one-Samle Kolmogorov-Smirnov Pada tabel 2 sebagai berikut:

Tabel 2. Uji Normalitas

\begin{tabular}{|l|l|r|}
\hline \multicolumn{2}{|l|}{} & \multicolumn{1}{c|}{$\begin{array}{c}\text { Unstandardized } \\
\text { Residual }\end{array}$} \\
\hline $\mathrm{N}$ & Mean & 100 \\
\cline { 2 - 3 } Normal Parameters & Std. Deviation & .0000000 \\
\hline Most Extreme Differences & Absolute & 1.50542794 \\
\hline
\end{tabular}




\begin{tabular}{|l|l|r|}
\hline & Positive & .067 \\
\cline { 2 - 3 } & Negative & -.078 \\
\hline Test Statistic & .078 \\
\hline Asymp. Sig. (2-tailed) & $.141^{\mathrm{c}}$ \\
\hline a. Test distribution is Normal. & \\
\hline b. Calculated from data. & \\
\hline c. Lilliefors Significance Correction. \\
\hline
\end{tabular}

Dapat diketahui dari output diatas bahwa nialai Kolnogrof-Smirnof Z 0,078 dengan tingkat Asymp.Sign sebesar 0,141. Dimana data tersebut dapat dikatakan berdistribusi normal bila Asymp.Sign > alpha 0,05. Maka dapat disimpulkan bahwa data berdistribusi normal dan model regresi memenuhi asumsi normalitas.

2. Uji Multikolinieritas

Berikut Hasil uji multikolinieritas Pada tabel 3 di bawah ini dapat di lihat

Tabel 3. Uji Multikolinieritas

\begin{tabular}{|c|c|c|c|c|c|c|c|c|}
\hline & \multirow{2}{*}{ Model } & \multicolumn{2}{|c|}{$\begin{array}{l}\text { Unstandardized } \\
\text { Coefficients }\end{array}$} & \multirow{2}{*}{$\begin{array}{c}\begin{array}{c}\text { Standardized } \\
\text { Coefficients }\end{array} \\
\text { Beta }\end{array}$} & \multirow{2}{*}{$\mathbf{T}$} & \multirow{2}{*}{ Sig. } & \multicolumn{2}{|c|}{$\begin{array}{c}\text { Collinearity } \\
\text { Statistics }\end{array}$} \\
\hline & & B & $\begin{array}{l}\text { Std. } \\
\text { Error }\end{array}$ & & & & $\begin{array}{c}\text { Toleranc } \\
\text { e }\end{array}$ & VIF \\
\hline \multirow[t]{3}{*}{1} & (Constant) & 1.862 & 1.244 & & 1.497 & .138 & & \\
\hline & $\begin{array}{l}\text { PERSEWPSI } \\
\text { MANFAAT }\end{array}$ & .283 & .077 & .342 & 3.664 & .000 & .497 & 2.010 \\
\hline & $\begin{array}{l}\text { PERSEPSI } \\
\text { KEMUDAHAN }\end{array}$ & .493 & .096 & .479 & 5.129 & .000 & .497 & 2.010 \\
\hline
\end{tabular}

Berdasarkan nilai tolerance pada tabel di atas diketahui persepsi manfaatdan persepsi kemudahan yaitu $0,497>0.10$ maka dapat disimpulkan tidak terjadi multikolinieritas. Berdasarkan nilai VIF pada tabel di atas diketahui persepsi manfaat dan Persepsi kemudahan yaitu $2.010<10,00$ maka dapat disimpulkan bahwa tidak terjadi multikolinieritas. Dapat di simpulkan bahwa data bebas dari gejala multikolinieritas.

3. Uji Heterokedastisitas

Hasil uji heterokedasstisitas, Grafik scatter plot dapat di lihat pada gambar 2.

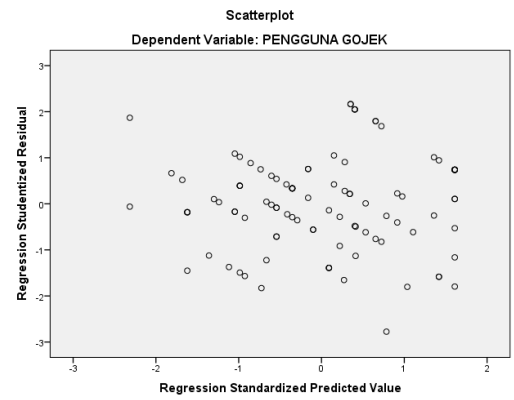

Gambar 2. Grafik scatter plot Heterokedastisitas 
Pada gambar 2 terlihat bahwa titik-titik menyebar secara acak serta tersebar baik di atas maupun di bawah angka 0 pada sumbu Y. hal ini dapat disimpulkan bahwa tidak terjadi Heterokedastisitas pada model regresi.

4. Analisis Regresi Linier Berganda

Hasil analisis linier berganda dapat dilihat pada tabel 4

Tabel 4. Analisis Regresi Linier Berganda

\begin{tabular}{|c|c|c|c|c|c|c|}
\hline \multirow{2}{*}{\multicolumn{2}{|c|}{ Model }} & \multicolumn{2}{|c|}{$\begin{array}{l}\text { Unstandardized } \\
\text { Coefficients }\end{array}$} & \multirow{2}{*}{$\begin{array}{c}\text { Standardized } \\
\text { Coefficients }\end{array}$} & \multirow[b]{2}{*}{$\mathrm{t}$} & \multirow[b]{2}{*}{ Sig. } \\
\hline & & $\mathrm{B}$ & Std. Error & & & \\
\hline \multirow[t]{3}{*}{1} & (Constant) & 1.862 & 1.244 & & 1.497 & .138 \\
\hline & PERSEPSI MANFAAT & .283 & .077 & .342 & 3.664 & .000 \\
\hline & PERSEPSI KEMUDAHAN & .493 & .096 & .479 & 5.129 & .000 \\
\hline
\end{tabular}

a. Persamaan Regresi Linier Berganda

$\mathrm{Y}=0,342(\mathrm{x} 1)+0,479(\mathrm{x} 2)$

b. Mengartikan Koifisien Fariabel Independen Dalam Persamaan Regresi

Berganda. Dimana $\mathrm{Y}=0,342(\mathrm{x} 1)+0,479(\mathrm{x} 2)$

5. Uji Hipotesis

a. Uji t

Secara persial, pengujian hipotesisi dilakukan dengan uji t (t-test). Menurut Gozali (2012: 98) uji statistik t pada dasarnya menunjukkan seberapa jauh pengaruh suatu variabel penjelas/independen secara individual dalam menerangkan variabel dependen secara persial. Uji ini dilakukan dengan membandingkan signifikansi t hitung dengtan $t$ table hasil Uji $t$ dapat dilihat Pada tabel 5.

Tabel 5. Uji t

\begin{tabular}{|l|l|r|r|r|r|r|}
\hline \multicolumn{2}{|c|}{\multirow{2}{*}{ Model }} & \multicolumn{2}{|c|}{$\begin{array}{c}\text { Unstandardized } \\
\text { Coefficients }\end{array}$} & $\begin{array}{c}\text { Standardized } \\
\text { Coefficients }\end{array}$ & \multirow{2}{*}{ t } & \multirow{2}{*}{ Sig. } \\
\cline { 3 - 5 } \multicolumn{2}{|c|}{} & \multicolumn{1}{c|}{ B } & Std. Error & Beta & & \\
\hline \multirow{3}{*}{1} & (Constant) & 1.862 & 1.244 & & 1.497 & .138 \\
\cline { 2 - 7 } & PERSEWPSI MANFAAT & .283 & .077 & .342 & 3.664 & .000 \\
\cline { 2 - 7 } & PERSEPSI KEMUDAHAN & .493 & .096 & .479 & 5.129 & .000 \\
\hline
\end{tabular}

$\alpha=0,05$

$\mathrm{N}=100$

$\mathrm{K}=2$

$\mathrm{t}$ tabel $=\mathrm{t}(\alpha / 2: \mathrm{n}-\mathrm{k}-1)$

$\mathrm{t} \quad=0,025: 97$

Dik nilai sig persepsi manfaat $0,00<0,05$ dan nilai t hitung $3.664>\mathrm{t}$ Tabel 1,98472 artinya Terdapat pengaruh positif persepsi manfaatterhadap penggunaan aplikasi GoFood pada masyrakat di Kota Mataram

Dik nilai sig perceived ease of uses $0,00<0,05$ dan nilai t hitung 5,129>t Tabel t 1,98472 artinya Terdapat pengaruh popsitif persepsi kemudahan terhadap penggunaan aplikasi GoFood pada masyrakat di Kota Mataram.

b. Uji F 
Hasil uji f dapat di lihat pada tabel 6 .

Tabel 6. Uji F

\begin{tabular}{|l|l|r|r|r|r|r|}
\hline \multicolumn{2}{|l|}{ Model } & Sum of Squares & Df & Mean Square & F & \multicolumn{1}{c|}{ Sig. } \\
\hline \multirow{3}{*}{1} & Regression & 308.635 & 2 & 154.317 & 66.716 & $.000^{\mathrm{b}}$ \\
\cline { 2 - 7 } & Residual & 224.365 & 97 & 2.313 & & \\
\cline { 2 - 7 } & Total & 533.000 & 99 & & & \\
\hline
\end{tabular}

Berdasarkan tabel di atas terlihat bahwa $\mathrm{F}$ hitung sebesar 66.716 dengan probabilita serbesar 0.000 yang berarti nilai probabilita sig karena $<0.05$. sedangkan hasil dari $\mathrm{F}$ tabel dengan $\mathrm{df} 1=2$ dan $\mathrm{df} 2=97$ pada $\alpha 0.05$ sebesar 3,090. Artunya $\mathrm{F}$ hitung $>\mathrm{F}$ tabel $(66.716>3.090)$. maka dari itu dapat di simpulkan semua variable independen (persepsi kemanfaatan dan persepsi kemudahan penggunaan) layak untuk menjelaskan variable dependen.

\section{Hasil Penelitian}

Adapun hasil penelitian terhadap variabel-variabel yang terdapat dalam penelitian ini, dapat dijelaskan dalam tabel 7 berikut.

Tabel 7. Hasil Penelitian

\begin{tabular}{|l|l|c|c|l|}
\hline No & \multicolumn{1}{|c|}{ Hipotesis } & $\boldsymbol{1}$ & \multicolumn{1}{|c|}{ Signifikansi } & \multicolumn{1}{|c|}{ Kesimpulan } \\
\hline 1 & $\begin{array}{l}\text { Pengaruhpersepsi kemanfatan terhada Penggunaan } \\
\text { Aplikasi Layanan GoFood Pada Masyrakat di Kota } \\
\text { Mataram }\end{array}$ & $\begin{array}{l}\text { Positif dan } \\
\text { signifikan }\end{array}$ \\
\hline 2 & $\begin{array}{l}\text { Pengaruh persepsi kemudahan terhadap penggunaan } \\
\text { layanan aplikasi GoFood pada masyarakat di kota } \\
\text { Mataram. }\end{array}$ & 0.479 & 0.000 & $\begin{array}{l}\text { Positif dan } \\
\text { signifikan }\end{array}$ \\
\hline
\end{tabular}

Berdasarkan hasil pengujian $\mathrm{H} 1$ membuktikan bahwa terdapat pengaruh positif dan signifikan persepsi kemanfaatan terhadap penggunaan aplikasi GoFood. Di Kota Mataram. Melalui hasil perhitungan yang telah di lakukan di peroleh nilai t hitung 3.664 lebih besar dari t tabel sebesar 1.98472 dan taraf sig 0.00 lebih kecil dari 0.05 dan koefisien regresi memiliki nilai positif sebesar 0.342 dengan demikian Ha di terima dan Ho di tolak. Pengujian ini secara statistik menunjukan bahwa persepsi kemanfaatan berpengaruh positif dan signifikan terhadap penggunaan aplikasi GoFood pada masyrakat di Kota Mataram.

Persepsi kemanfaatan secara umum didefinisikan sebagai sejauh mana seseorang yakin bahwa menggunakan suatu teknologi akan meningkatkan kinerja pekerjaannya. Persepsi tersebut dapat digunakan sebagai salah satu kriteria untuk mengetahui seberapa jauh sistem informasi yang dalam hal ini adalah GoFood memberikan manfaat oleh pengguna. Pengguna yang beranggapan bahwa aplikasi GoFood tersebut dapat berguna bagi dirinya, maka dia dengan senang hati akan mengakses aplikasi tersebut yang secara langsung akan berpengaruh pula terhadap minat melakukan transaksi pembelian. Hal ini di perkuat dengan hasil penelitian Periambodo (2016) bahwa persepsi manfaat berpengaruh positif pada penggunaan minat menggunakan uang elektronik.

Hasil pengujian $\mathrm{H} 2$ membuktikan bahwa terdapat pengaruh positif dan signifikan persepsi kemudahan terhadap penggunaan aplikasi layanan GoFood. Di Kota Mataram.baik dalam perhitungan regresi linier berganda dan uji $\mathrm{t}$ Melalui hasil perhitungan yang telah dilakukan di peroleh t hitung 5.129 lebih besar dari t tabel 1.98472 dan taraf sig 0,00 lebih kecil dari 0,05 dan koefisien regresi memiliki nilai positif sebesar 0,479 dengan demikian Ha di terima dan Ho di tolak. Pengujian ini 
secara statistik menunjukan bahwa persepsi kemudahan penggunaan berpengaruh positif terhadap penggunaan aplikasi GoFood pada masyrakat di Kota Mataram.

Persepsi kemudahan penggunaan merupakan suatu tingkat atau keadaan di mana seseorang yakin bahwa dengan menggunakan sistem tertentu tidak diperlukan usaha apapun. GoFood adalah jasa mengantar makanan yang ada pada aplikasi Gojek. Usaha merupakan sumber yang terbatas yang akan dialokasikan seseorang pada sebuah aktivitas sebagai bentuk dari tanggung jawab. Aplikasi GoFood sebagai salah satu bentuk implementasi teknologi dapat digunakan sebagai parameter untuk menilai sejauh mana minat pengguna terhadap fitur dan karakteristik yang ada pada aplikasi itu sendiri. Pengguna yang beranggapan bahwa aplikasi layanan GoFood mudah untuk diakses dan mudah untuk dipahami, maka dirinya akan senantiasa mengakses aplikasi tersebut untuk melakukan transaksi pembelian secara online berupa makanan.

Hasil penelitian ini mendukung Penelitian yang dilakukan oleh Mimba (2016) bahwa Persepsi kemudahan penggunaan berpengaruh positif terhadap penggunaan internet banking pada usaha dagang di kota Denpasar

Dari hasi uji linier berganda dapat di lihat bahwa Persepsi kemudahan memiliki pengaruh paling dominan sebesar 0.479 terhadap penggunaan Aplikasi GoFood pada masyrakat di Kota Mataram.

Ini berarti Persepsi kemudahan penggunaan yang dirasakan pada penggunaan aplikasi GoFood pada masyrakat di Kota Mataram yaitu tidak di butuhkan banyak usaha untuk berinteraksi dengan sistem yang ada pada tersebut. Sistem aplikasi GoFood sangat mudah digunakan. Kemudahan akan berdampak pada perilaku, yaitu semakin tinggi persepsi seseorang tentang kemudahan menggunakan teknologi, maka semakin tinggi pula tingkat pemanfaatan teknologi informasi. Dapat diketahui bahwa kemudahan penggunaan merupakan suatu keyakinan tentang proses pengambilan keputusan. Jika seseorang yakin dengan teknologi yang ada dan mudah untuk digunakan maka seseorang akan sering menggunakannya.

Penelitian ini mendukung penelitian yang dilakukan Nursiah (2017) pengaruh Persepsi kemudahandan persepsi manfaatterhadap behavior intention to use. Hasil penelitiannya menyatakan bahwa variabel yang lebih dominan adalah Persepsi kemudahan terhadap behavior intention to use.

Hasil penelitian ini memberikan gambaran perilaku konsumen terhadap perubahan perilaku masyarakat, yaitu dalam memutuskan menggunakan sesuatu yang baru. Dalam hal ini mengunakan fitur GoFood dalam aplikasi Gojek. Konsumen di kota Mataram menggunaka fitur GoFood dalam aplikasi Gojek karena memberikan kemanfaatan dan kemudahan penggunaan. Hal ini sesuai dengan Model TAM yang diperkenalkan oleh Davis (1989) yang mengembangkan kerangka pemikiran mengenai minat untuk menggunakan tekhnologi berdasarkan persepsi manfaat (perceived of usefulness) dan persepsi kemudahan penggunaan (perceived ease of use). Sejalan juga dengan pendapatnya Thompson (1991) yang menyatakan bahwa individu akan menggunakan teknologi informasi tersebut, jika orang tersebut mendapatkan kemanfaatan dan kemudahan dalam menggunakan nya.

\section{KESIMPULAN DAN SARAN}

\section{Kesimpulan}

Kesimpulan yang dapat ditarik dari penelitian ini adalah:

1. Persepsi manfaat berpengaruh positif dan signifikan terhadap penggunaan layanan Aplikasi GoFood pada masyarakat di kota Mataram. 
2. Persepsi kemudahan berpengaruh positif dan signifikan terhadap penggunaan layanan aplikasi GoFood pada masyarakat kota Mataram.

3. Persepsi kemudahan merupakan faktor yang lebih dominan berpengaruh terhadap Penggunaan layanan aplikasi GoFood pada masyarakat di kota Mataram.

\section{Saran}

Bertolak dari hasil penelitian, maka dapat diajukan saran kepada PT. Gojek, khususnya di kota Mataram sebaiknya mengoptimalkan manfaat dan kemudahan yang dirasakan pengguna layanan fitur GoFood di aplikasi Gojek, karena manfaat yang dirasakan tersebut tentu menambah citra dan loyalitas pengguna dan mengoptimalkan pelayanan kepada konsumen, dengan memberikan jaminan keamanan dan kenyamanan pada saat berinteraksi. Hal ini bertujan agar minat konsumen menggunakan layanan fitur GoFood dapat semakin meningkat, sehingga dapat mendatangkan keuntungan yang maksimal.

\section{DAFTAR PUSTAKA}

Bhilawa, L.2010. Analisis Penerimaan Mobile Banking (m-banking) dengan pengalaman (Experience) sebagai variabel External dengan menggunakan Pendekatan Technogy Acceptance Model (TAM). Skripsi Sarjana Fakultas Ekonomi Universitas Sebelas Maret Surakarta.

Davis, F.D. 1989. Perceived Usefulness, Perceived Ease of Use and User Acceptance of Information Technology. MIS Quarterly. Vol.13 No.5: pp319-339.

Dastgir, M, and A. S. Morteznie. 2012. "Factors Affeefting The End-User Computing Satisfaction". Business Integence Journal,55(2):292:298.

Ghozali, Imam. 2012. Aplikasi Analisis Multi Variate dengan Program IBM SPSS19. Semarang: Badan Penerbit Universitas Diponegoro.

Jogiyanto, Hm. 2007. Sistem Informasi Keperilakuan. Yogjakarta: Andi.

Kadir, Abdul. 2003. Pengendalian Sistem Informasi Keperilakuan. Yogjakarta: Andi.

Nasution. 2004. Perceived of Use, Sistem Informasi Manajemen. Sanjaya.

Santoso, B. 2014. Pengaruh perceived Usefulness, Perceived Ease of Use dan Perceived Enjoyment Terhadap Penerimaan Teknologi Informasi (Studi Empiris di Kabupaten Sragen).

Sugiyono. 2018. Metode Penelitian Kuantitatif, Kualitatif dan R\&D. Bandung: Alfabeta.

Trissantama, Lucky. (20120. Model Penerimaan Teknologi dalam Penggunaan Facebook Sebagai Media Promosi. Skripsi FISIP Universitas Lampung. Lampung.

Winayu, N.Y. (2013). Pengaruh Kepercayaan Perceived Ease of Use dan Percived Usefulness terhadap Minat Menggunakan E- Commerce Forum Jual Beli Kaskus. Skripsi UNY. Yogjakarta. 